WHOI-89-10

\title{
The 17-Meter Flume at the Coastal Research Laboratory. Part I: Description and User's Manual
}

\author{
by \\ Cheryl Ann Butman \\ and Robert J. Chapman \\ Woods Hole Oceanographic Institution \\ Woods Hole, Massachusetts 02543
}

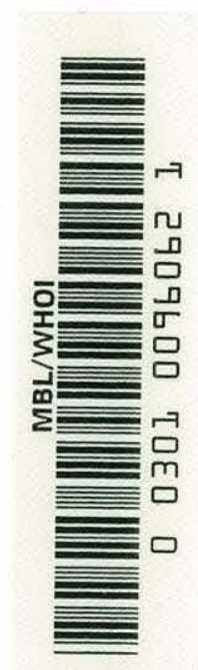

May 1989

Funding was provided by the Minerals Management Service under contract Number 14-12-0001-30262;

Sea Grant under contract Number NA86-AA-D-SG090; the Office of Naval Research

Young Investigator Program under contract

Number N00014-86-K-0579; and the Walter A. and Hope Noyes Smith

Special Studies Award.

Reproduction in whole or in part is permitted for any purpose of the

United States Government. This report should be cited as:

Woods Hole Oceanog. Inst. Tech. Rept., WHOI-89-10. CRC-89-2.

Approved for publication; distribution unlimited.

Approved for Distribution:

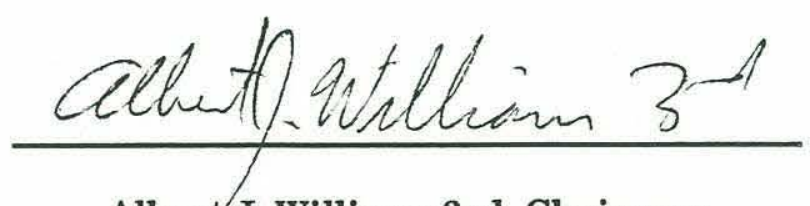

Albert J. Williams 3rd, Chairman

Department of Applied Ocean Physics and Engineering 


\title{
THE 17-METER FLUME AT THE COASTAL RESEARCH LABORATORY. PART I: DESCRIPTION AND USER'S MANUAL
}

\author{
Cheryl Ann Butman \\ and Robert J. Chapman \\ Ocean Engineering Department \\ Woods Hole Oceanographic Institution \\ Woods Hole, Massachusetts 02543
}




\begin{abstract}
The 17-Meter Flume, a recirculating, temperature-controlled, seawater channel, was recently constructed in W.H.O.I.'s Coastal Research Laboratory for studies of boundary-layer flows and sediment transport, and for interdisciplinary research where adequate simulation of the near-bed flow environment is required. The flume channel is $17.3-\mathrm{m}$ long by $0.6-\mathrm{m}$ wide and can be filled to a maximum depth of $0.3 \mathrm{~m}$. The water is circulated by a centrifugal pump and is temperature controlled to $\pm 0.5^{\circ} \mathrm{C}$ over a range of about $4-30^{\circ} \mathrm{C}$. Made of fiberglass, glass, plastics and high-grade stainless steel, all surfaces of the flume that come into contact with the water are noncorrosive and nontoxic to organisms. The flume is equipped with a computer-controlled, two-axis, laser-Doppler velocimeter (LDV) for detailed, accurate and precise measurements of flow characteristics anywhere along the flume channel. In addition to detailed descriptions and illustrations of all components of the flume, this report provides instructions for use of the flume and associated instrumentation. In Part II, flume flow characteristics measured with the LDV are illustrated and evaluated relative to theoretical and empirical expectations for open-channel flows.
\end{abstract}




\section{Contents}

$\begin{array}{ll}\text { List of Figures } & 3\end{array}$

List of Symbols $\quad 4$

1 INTRODUCTION 6

2 DESCRIPTION OF THE FLUME AND ASSOCIATED INSTRUMEN$\begin{array}{ll}\text { TATION } & 7\end{array}$

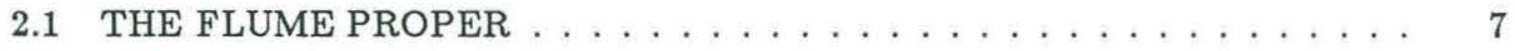

2.1 .1 The Raceway . . . . . . . . . . . . . . . . 7

2.1.2 The Collection Basin . . . . . . . . . . . . . . . . 10

2.1.3 The Circulation System . . . . . . . . . . . . . . . 10

2.2 THE LASER DOPPLER VELOCIMETER . . . . . . . . . . . . . . . . . . 10

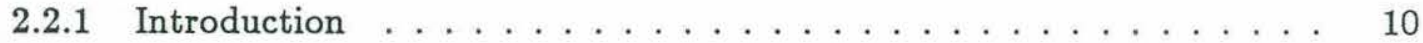

2.2 .2 Background ........................... 11

2.2.3 The Two Axis, Forward-Scatter System . . . . . . . . . . . . 11

2.2.4 Data Acquisition and Processing Software . . . . . . . . . . . 13

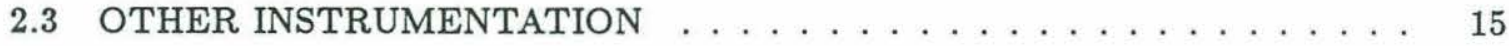

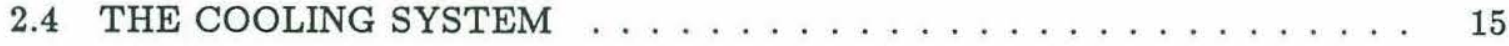

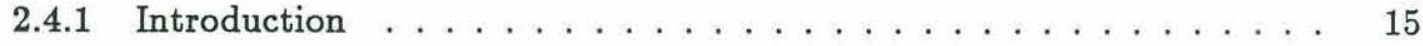

2.4 .2 Description ........................ 16

2.5 SAMPLE FLUME SETTINGS $\ldots \ldots \ldots \ldots \ldots \ldots \ldots \ldots \ldots$

3 INSTRUCTIONS FOR USE $\quad 20$

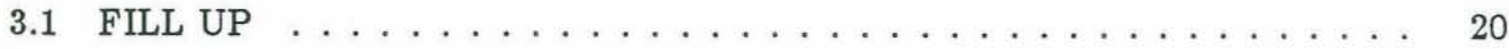

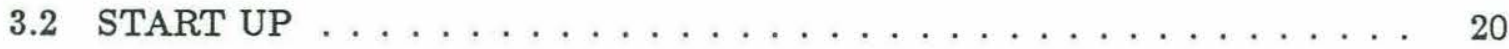


3.2 .1 Shut Down . . . . . . . . . . . . . . . . . . 21

3.3 LDV OPERATION . . . . . . . . . . . . . . . . . . . . 23

3.3.1 General Comments . . . . . . . . . . . . . . . . . . . . 23

3.3 .2 Start Up. . . . . . . . . . . . . . . . . . . 23

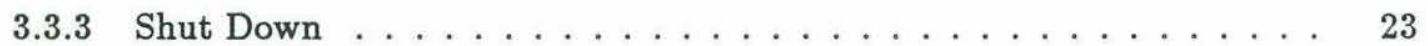

3.3.4 Software- Main Menu . . . . . . . . . . . . . . . . . 24

3.3.5 Laser Movement . . . . . . . . . . . . . . . . . . . 24

3.3.6 Measurement Parameters . . . . . . . . . . . . . . 25

3.3.7 Measurement Options . . . . . . . . . . . . . . 25

3.4 COOLING SYSTEM OPERATION $\ldots \ldots \ldots \ldots \ldots \ldots \ldots$

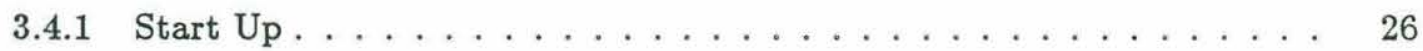

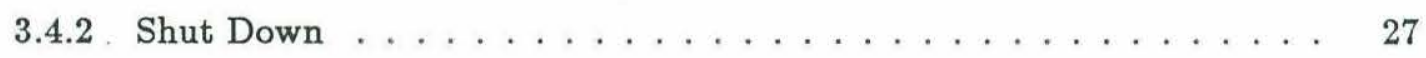

4 ACKNOWLEDGMENTS $\quad 27$

5 LITERATURE CITED $\quad 28$

$\begin{array}{llr}6 & \text { APPENDIX I } & 29\end{array}$

6.1 LASER GEOMETRY . . . . . . . . . . . . . . . . . . . . . . . . . 29

6.1.1 Measurement Orientation . . . . . . . . . . . . . . . 29

6.1 .2 Beam Geometry . . . . . . . . . . . . . . . . . . . 29

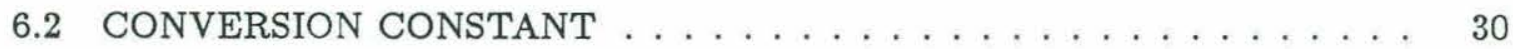

7 APPENDIX II $\quad 31$

7.1 FLUME OPERATION CHECKLIST: START UP . . . . . . . . . . . 31

7.2 FLUME OPERATION CHECKLIST: SHUT DOWN . . . . . . . . . . . . 31 


\section{List of Figures}

Figure 1: Perspective drawing, approximately to scale, of the 17-Meter Flume ...... 8

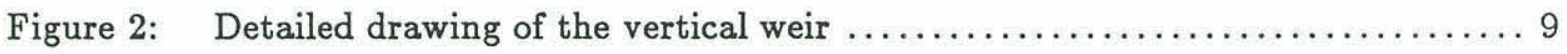

Figure 3: Two panels of the flume false bottom $\ldots \ldots \ldots \ldots \ldots \ldots \ldots \ldots \ldots \ldots \ldots$

Figure 4: Diagram of the fringe pattern at the intersection of two laser beams $\ldots \ldots \ldots 11$

Figure 5: Schematic drawing of the laser-Doppler velocimeter $\ldots \ldots \ldots \ldots \ldots \ldots \ldots \ldots 12$

Figure 6: Sample of the data screen for the LDV software package $\ldots \ldots \ldots \ldots \ldots \ldots 14$

Figure 7: Schematic drawing of the flume cooling system $\ldots \ldots \ldots \ldots \ldots \ldots \ldots \ldots \ldots$

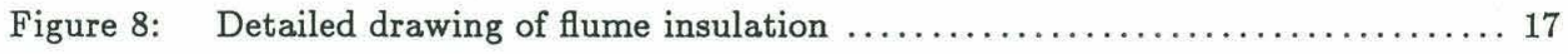

Figure 9: Profiles of mean velocity and Reynolds stress for a selection of flows ...... 19

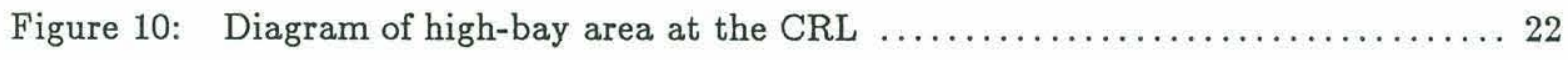




\section{List of Symbols}

\begin{tabular}{|c|c|c|}
\hline Symbol & Definition & Dimensions* \\
\hline$A, B$ & the two velocity channels of the LDV & - \\
\hline$c$ & $\begin{array}{l}\text { distance between two laser beams at } \\
\text { a distance } d \text { from their intersection }\end{array}$ & $\mathrm{L}$ \\
\hline$d$ & $\begin{array}{c}\text { distance from intersection of two laser } \\
\text { beams to } c\end{array}$ & $\mathrm{~L}$ \\
\hline$f_{D}$ & difference frequency & $\mathrm{T}^{-1}$ \\
\hline$g$ & gravitational acceleration & $\mathrm{L} \mathrm{T}^{-2}$ \\
\hline$h$ & water depth & $\mathrm{L}$ \\
\hline$H$ & pressure head & $\mathrm{L}$ \\
\hline$\lambda$ & wavelength of laser beam & $\mathrm{L}$ \\
\hline$n$ & refractive index of fluid & - \\
\hline$\rho$ & fluid density & $\mathrm{M} \mathrm{L}^{-3}$ \\
\hline$Q$ & volume discharge rate & $\mathrm{L}^{3} \mathrm{~T}^{-1}$ \\
\hline$\tau_{b}$ & mean bottom shear stress & $\mathrm{M} \mathrm{L} \mathrm{T} \mathrm{T}^{-2}$ \\
\hline$u$ & instantaneous streamwise velocity & $\mathrm{L} \mathrm{T}^{-1}$ \\
\hline$u^{\prime}$ & fluctuating component of $u$ & $\mathrm{~L} \mathrm{~T}^{-1}$ \\
\hline $\bar{u}$ & mean component of $u$ & $\mathrm{~L} \mathrm{~T}^{-1}$ \\
\hline$u_{*_{R}}$ & $\begin{array}{l}\text { shear velocity determined using } \\
\text { Reynolds stress technique }\end{array}$ & $\mathrm{L} \mathrm{T}^{-1}$ \\
\hline$U_{p}$ & particle velocity & $\mathrm{L} \mathrm{T}^{-1}$ \\
\hline
\end{tabular}




\begin{tabular}{ccc} 
Symbol & Definition & Dimensions* \\
\hline$w$ & instantaneous vertical velocity & $\mathrm{L} \mathrm{T}^{-1}$ \\
$w^{\prime}$ & fluctuating component of $w$ & $\mathrm{~L} \mathrm{~T}^{-1}$ \\
$\bar{w}$ & mean component of $w$ & $\mathrm{~L} \mathrm{~T}^{-1}$ \\
$x$ & streamwise (parallel to channel) coordinate & $\mathrm{L}$ \\
$y$ & cross-stream coordinate & $\mathrm{L}$ \\
$z$ & vertical coordinate & $\mathrm{L}$ \\
\hline
\end{tabular}

${ }^{*} \mathrm{~L}=$ length, $\mathrm{M}=$ mass, $\mathrm{T}=$ time 


\section{INTRODUCTION}

The growing interest in coastal-ocean processes during the last decade has accentuated the need for laboratory facilities where various aspects of the coastal-ocean environment can be simulated under controlled conditions. Laboratory flumes that can simulate flow regimes dynamically similar to those occurring in coastal waters are required because hydrodynamics is the backdrop for all ocean processes. Such flumes can be used for direct, detailed studies of the hydrodynamics, as well as for interdisciplinary studies of the interaction of the flow with other (e.g., geological, biological or chemical) phenomena. While there are numerous flumes and flume facilities both nationally and internationally, of those which have the proper dimensions and flow forcing for simulating a wide range of steady, coastal-ocean flows, few can be filled with seawater or are temperature-controlled, severely limiting their application to interdisciplinary studies of marine processes.

The 17-Meter Flume, a recirculating, temperature-controlled, seawater channel constructed in the Coastal Research Laboratory at Woods Hole Oceanographic Institution, was specifically designed for studies of biogeochemical and fluid-dynamical questions which can be adequately addressed in a steady-flow environment. It was designed to generate the range of flow speeds and shear stresses typical of boundary-layer flows in coastal-ocean waters. While it was modeled primarily after the "O.6 Metre Flume" at Canada's National Water Research Institute Hydraulics Laboratory in Burlington, Ontario (NWRI, 1982), the design is typical of other freshwater flumes used in studies of high Reynolds number, open-channel flows (e.g., Nezu \& Rodi, 1986) and sediment transport (e.g., Vanoni, 1946). In contrast to most other flumes, however, the 17-Meter Flume does not have a large head tank, is temperaturecontrolled to $\pm 0.5^{\circ} \mathrm{C}$ over a range of about $4-30^{\circ} \mathrm{C}$, and all surfaces which come into contact with the water are noncorrosive and nontoxic to marine organisms. It is equipped with a twoaxis, forward-scatter, laser-Doppler velocimeter, that is automated and computer-controlled for state-of-the-art measurements of flow characteristics anywhere in the 17.3-m-long channel.

Dr. William D. Grant (Ocean Engineering Department, WHOI) conceived the 17-Meter Flume, and supervised the design and construction until his unexpected death in October 1986. We completed the construction during 1986 and 1987, and diagnostic studies of flume flow characteristics were carried out during 1987 and 1988. Our description of the flume facility is broken into two parts. Part I (this report) provides comprehensive descriptions of the flume and associated instrumentation, examples of flume settings to achieve selected flow regimes, and detailed instructions for the use of this facility. Part II (Trowbridge et al., 1989) evaluates measured characteristics of flow in the 17-Meter Flume relative to theoretical and empirical expectations. In addition, the design criteria and a more detailed description of the flume cooling system is given in Chapman \& Galat (1988). 


\section{DESCRIPTION OF THE FLUME AND ASSOCIATED INSTRUMENTATION}

\subsection{THE FLUME PROPER}

The 17-Meter Flume (refer to Fig. 1) is a recirculating system capable of producing a wide range of flow regimes. The flow regimes develop in the raceway as the water, driven by gravity, flows down the channel. The outflow from the raceway falls into one of two collection basins. The circulation system draws from the sump basin and provides a continuous supply of water to the headbox. The resulting flow regime varies as a function of raceway slope, the downstream weir setting, and volumetric flow rate.

\subsubsection{The Raceway}

The raceway is a rectangular channel $17.3 \mathrm{~m}$ in length with a cross section $60 \mathrm{~cm}$ wide by $30 \mathrm{~cm}$ deep. The raceway is constructed of molded fiberglass and supported on two steel I-beams. The channel is joined to the beams with bolts allowing for fine-tuning of the channel elevation. The raceway has a pivot at the downstream end and is supported by hydraulic jacks at the upstream end. Raising the jacks $1 \mathrm{~mm}$ increases the raceway slope 0.0044 degrees. The smooth-walled channel has plate glass windows at 8 locations along the raceway to allow viewing and LDV measurements of the flow. The windows, measuring $102-\mathrm{cm}$ long by $27-\mathrm{cm}$ high and 6.3-mm thick, are mounted flush with the sidewalls to minimize flow disturbance. To achieve a wide range of flow regimes there is a set of vertical blinds located $17 \mathrm{~m}$ downstream that act as a weir (Fig. 2). The weir controls the depth and discharge for a given slope.

The bottom of the fiberglass channel is below the lower edge of the viewing windows and prevents LDV measurements directly above the bottom of the raceway. Thus, a false bottom was constructed of 2-cm thick PVC (polyvinylchloride) panels to bring the bottom into view. The false bottom consists of 14 individual panels, $60-\mathrm{cm}$ wide by $1.22-\mathrm{m}$ long, that run the entire length of the raceway. The panels are joined at the seams with stainless steel pins to assure a smooth transition between the panels (Fig. 3). The 2-cm-thick panels are chosen to prevent buckling, and thus to create a perfectly smooth bottom. Some waviness exists, however, with maximum relief of $\sim 1 \mathrm{~mm}$. An analysis by J.H. Trowbridge (pers. comm.) of the potential effects of this relatively low-relief, wavy bed on the bottom shear stress (Kobayashi \& Madsen, 1985) for typical flume flow conditions revealed that the effect was negligible (a few percent).

Individual panels can be removed and replaced with sediment or panels modified for a particular experiment. For experiments requiring sediment depths greater than $2 \mathrm{~cm}$, the flume is equipped with a removable, deep sediment box. The box can be inserted at a location $12 \mathrm{~m}$ downstream centered in the raceway so that sediments are flush with the flume false bottom. The box, with inside dimensions of 48 - by 48 - by $36-\mathrm{cm}$ deep, has a false bottom that can be 


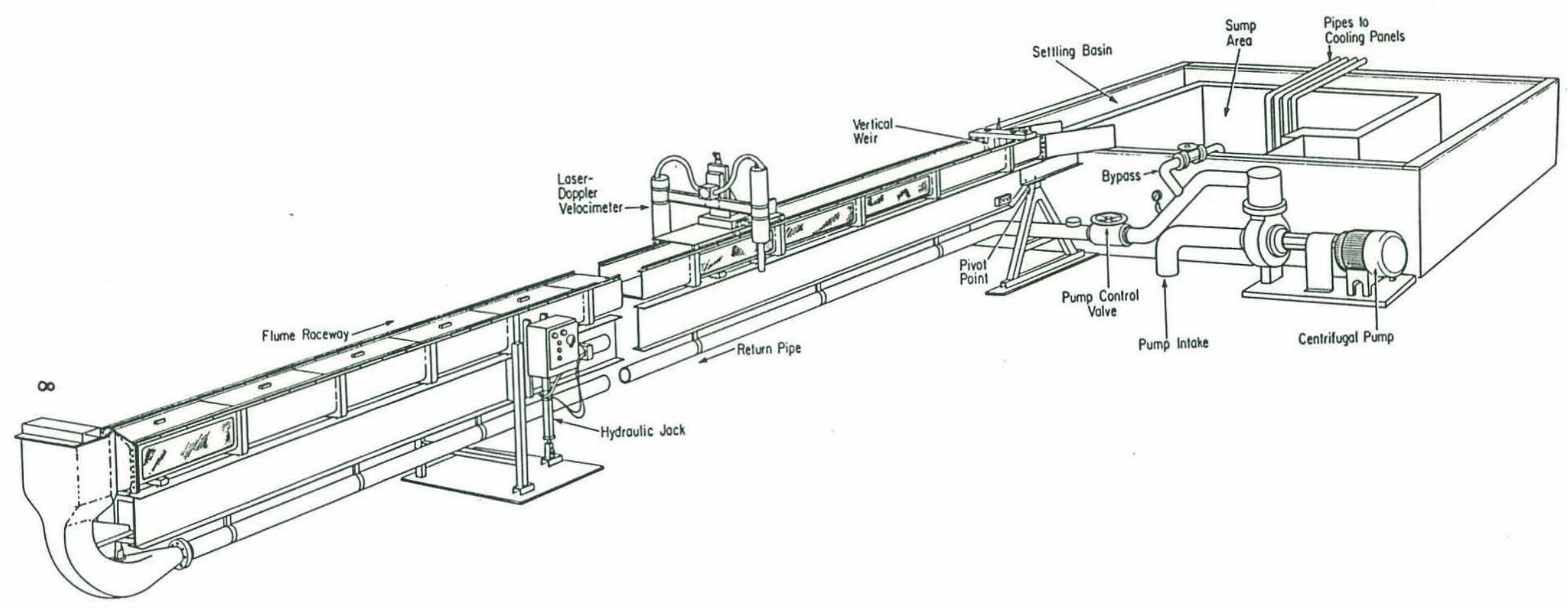

Figure 1: Perspective drawing, approximately to scale, of the 17-Meter Flume. The insulation panels (see Fig. 8) which normally cover the sides and bottom of the raceway have been removed to show more detail of the channel construction.

The wooden panels which rest on top of the entire raceway have been removed from the downstream region, again to expose detail within the flume channel. Enlarged drawings of the vertical weir and the flume false bottom are shown in Figures 2 and 3, respectively. Schematic drawings of the laser-Doppler velocimeter and the cooling system are shown in Figures 5 and 7, respectively. 
Figure 2: Detailed drawing of the vertical weir, located at the terminus of the flume raceway (see Fig. 1).
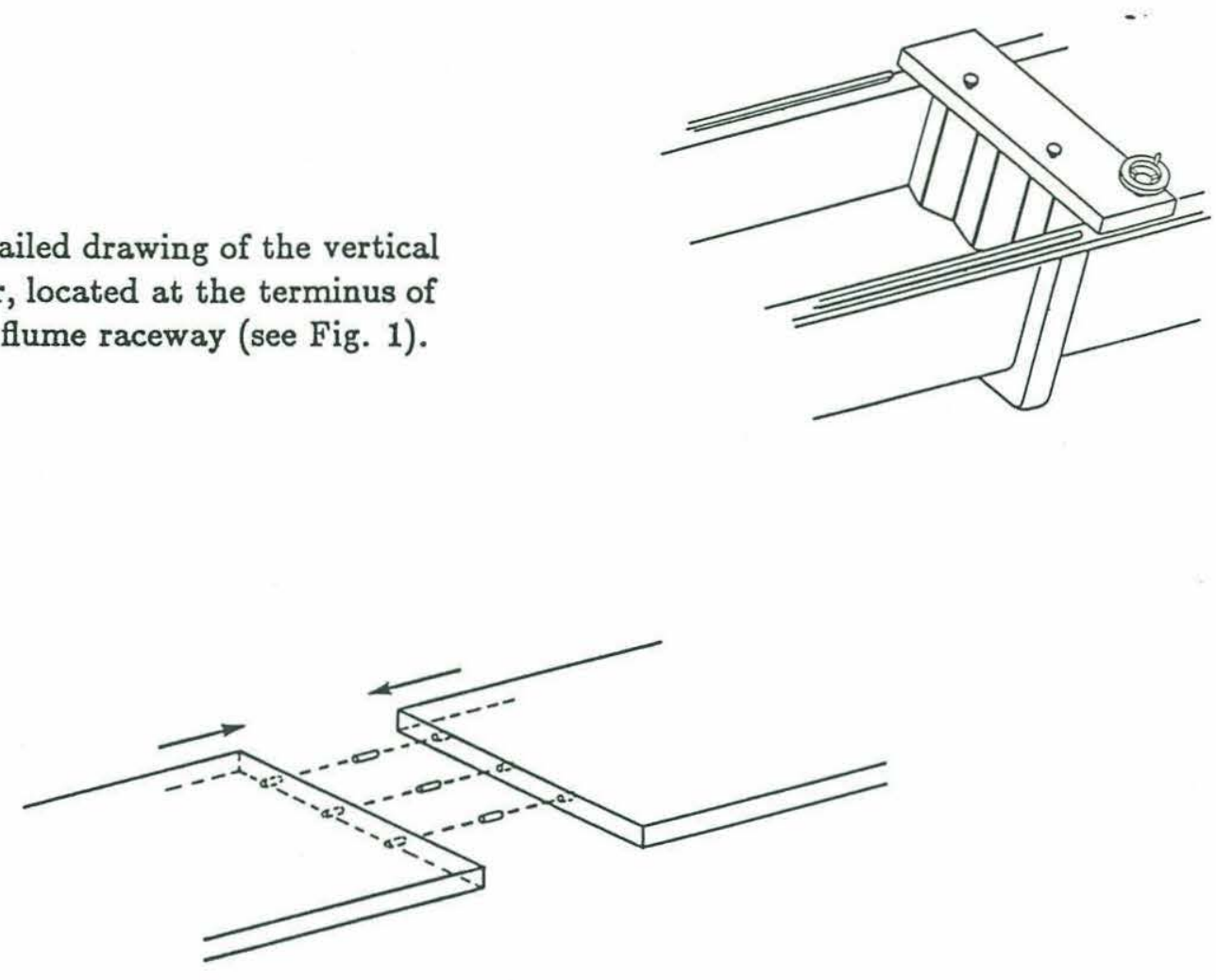

Figure 3: Two panels of the flume false bottom, showing how they are pinned together, making a completely smooth transition in surface texture between each panel.

raised in $5 \mathrm{~cm}$ increments. The dimensions of the opening in the bottom of the flume for this box also allows for insertion of a 50 - by $50-\mathrm{cm}$ box core taken from the field.

Attached to the entrance of the raceway is a headbox that provides a smooth transition from the turbulent flow in the return pipe to a flow in the entrance region. It is intended to minimize secondary circulation and surface waves. This transition is achieved through an expanding and turning section. The water first goes through an expanding section; then, it turns $90^{\circ}$ and heads straight up through another expanding section. The water is then at the level of the raceway where the flow is driven down the flume by gravity (and a horizontal pressure gradient if there is a significant surface slope) balanced by the frictional drag of the flume surfaces and inertial (i.e., acceleration) effects. The headbox contains both turning vanes to reduce cross-stream flows produced in the turn and a horizontally fixed plate to dampen surface waves. At the exit of the headbox there is a flow straightener, a plexiglass grid composed of $1.2 \mathrm{~cm}$ squares $7.5-\mathrm{cm}$ long, which limits secondary circulations that may have been introduced in the transition region. At the downstream end of the raceway a $\mathrm{Y}$-shaped section diverts the outflow into one of the two sections within the collection basin. 


\subsubsection{The Collection Basin}

The collection basin is constructed of 20 -cm-thick concrete walls painted with a USDA- and FDA-approved epoxy paint that is non-toxic to organisms. The collection area is composed of two tanks, a sump area and a settling basin. The system can be run using just the sump area or using the sump area and the settling basin. The sump area is 3.6 by $3.6 \mathrm{~m}$. The bottom is 1.3-m deep at the edges and slopes down to a depth of $2.1 \mathrm{~m}$ at the center, where the pumping system draws water to be circulated. The outflow pipe is covered with mesh to prevent the pump from being damaged by large debris. The sump area also contains heat exchangers for the cooling system (see 2.4 for detailed description). The panels are located directly over the outflow pipe. The settling basin is a $1.1-\mathrm{m}$ wide and $1.3-\mathrm{m}$ deep channel that wraps around the sump area. The settling basin drains into the sump area over a weir that is located in the wall which separates the two areas. Adjustment of the weir height allows flow through the settling basin that will permit particles of a specific size to settle out before reaching the weir, and thus preventing their recirculation from the collection area to the flume.

\subsubsection{The Circulation System}

The circulation system draws water from the sump basin using a centrifugal pump. The pump is driven by a $25 \mathrm{hp}$ electric motor and is capable of pumping liquid heavily laden with suspended matter (i.e., sediment slurries). The pump runs at a constant speed and is able to pump up to $0.095 \mathrm{~m}^{3} \mathrm{~s}^{-1}$ at $13.7 \mathrm{~m}$ total dynamic head. A valve between the pump and the raceway regulates the discharge of the pump. Located between the pump and the pump regulation valve, there is also a bypass valve that discharges back into the sump area. The bypass is used to maintain the efficiency of the pump when the system is circulating at low speeds. The bypass also increases the circulation of water over the heat exchangers to increase the efficiency of cooling system. The circulation system is constructed of non-toxic epoxy pipe, except the return pipe, which is made of $15-\mathrm{cm}$ diameter PVC. The return pipe extends the length of the flume below the raceway, from the pump regulation valve to the headbox.

\subsection{THE LASER DOPPLER VELOCIMETER}

\subsubsection{Introduction}

The flume is equipped with a two-axis, forward-scatter, laser-Doppler velocimeter (LDV) for non-intrusive and simultaneous measurements of the horizontal and vertical velocities at any point in the flow. The LDV is mounted on a cart that can be moved along the entire length of the flume. The cart is supported by rails that are attached to the top flanges of the channel. 
Laser velocimetry is unique in that the measurement does not result in the flow disturbances that are associated with other methods of flow measurement, like electromagnetic current meters and hot-film sensors. The only component of the instrument that contacts the water is the laser beam, which does not affect the flow. The velocity is computed using electro-optic techniques that extract the velocity of the flow from the laser light scattered as small particles pass through the intersection of the laser beams.

\subsubsection{Background}

The fringe model is a useful tool for understanding the basic principles of laser velocimetry. For a more comprehensive treatment see, for example, Durst et al. (1976). An interference pattern is created when two laser beams intersect. This fringe pattern, as shown in Figure 4, contains bright and dark zones that develop due to the wave characteristics of light. The physical characteristics of the fringe pattern are a function of the frequency and geometry of the two intersecting laser beams. This fringe pattern develops in the plane that is defined by the center lines of the two intersecting beams. Particles that are traveling in this plane and cross through the intersection volume scatter light as they travel through the bright zones.

Figure 4: Diagram of the fringe pattern which occurs within the measurement volume, at the intersection of two laser beams.

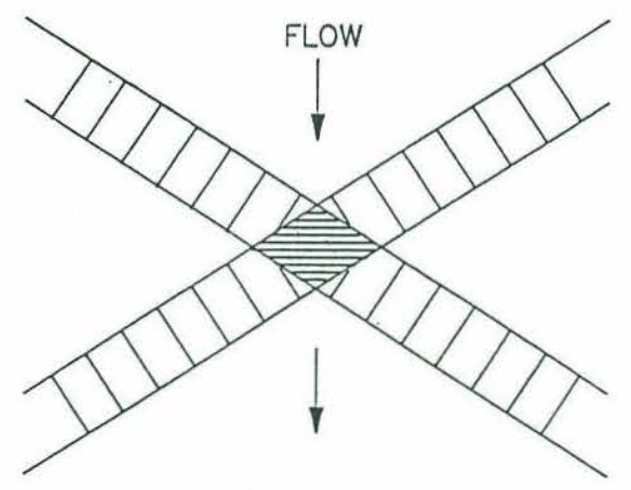

The frequency of the scattered light is proportional to the speed of the particles traveling through the fringe pattern. This is because of the "Doppler effect", where the motion of the particles passing through the light changes its apparent frequency, a concept described formally by Christian Doppler in the mid 1800's (e.g., see Toman, 1984). The Doppler signal produced by a particle traveling through a standing fringe pattern does not contain directional information. Particles traveling at the same speed in opposite directions produce identical Doppler signals. Shifting the frequency of the intersecting beams by a known amount creates a fringe pattern that is traveling at a known velocity. Thus, particles traveling through the fringe pattern at the same speed in opposite directions produce unique Doppler signals.

\subsubsection{The Two Axis, Forward-Scatter System}

Designed and constructed in Dr. Yogi Agrawal's laboratory, this LDV system is a duplicate of a field system (Agrawal \& Belting, 1988) used on SEADUCT (see description in 
Nowell et al., 1985), and measures two axes of velocity at a point in the flume. This allows for simultaneous estimates of the horizontal and the vertical velocities, which can be used to describe a two-dimensional flow. The system is configured in forward-scatter mode, meaning that the Doppler signal is received at an angle of $180^{\circ}$ from the optics that produce the laserbeam intersection point. Forward scatter has the advantage of a high signal-to-noise ratio and allows the use of a relatively low-power laser.

The system, shown schematically in Figure 5, is composed of two optical systems. The sending optics consist of the laser, beam splitter, Bragg cells, beam shifter, and sending mirrors. The receiving optics consist of the receiving mirror, focusing lens, photodetector and electronics. The sending and receiving optics are each mounted within their own plexiglass cylinders. The two cylinders straddle the flume, supported on a platform by an aluminum Ibeam. The support beam is mounted to a computer-controlled, two-axis, stepper-motor stage. The steeper-motor assembly positions the laser in the vertical and cross-stream directions; the along-channel position is manually controlled by rolling the cart along the rails on top of the flume.

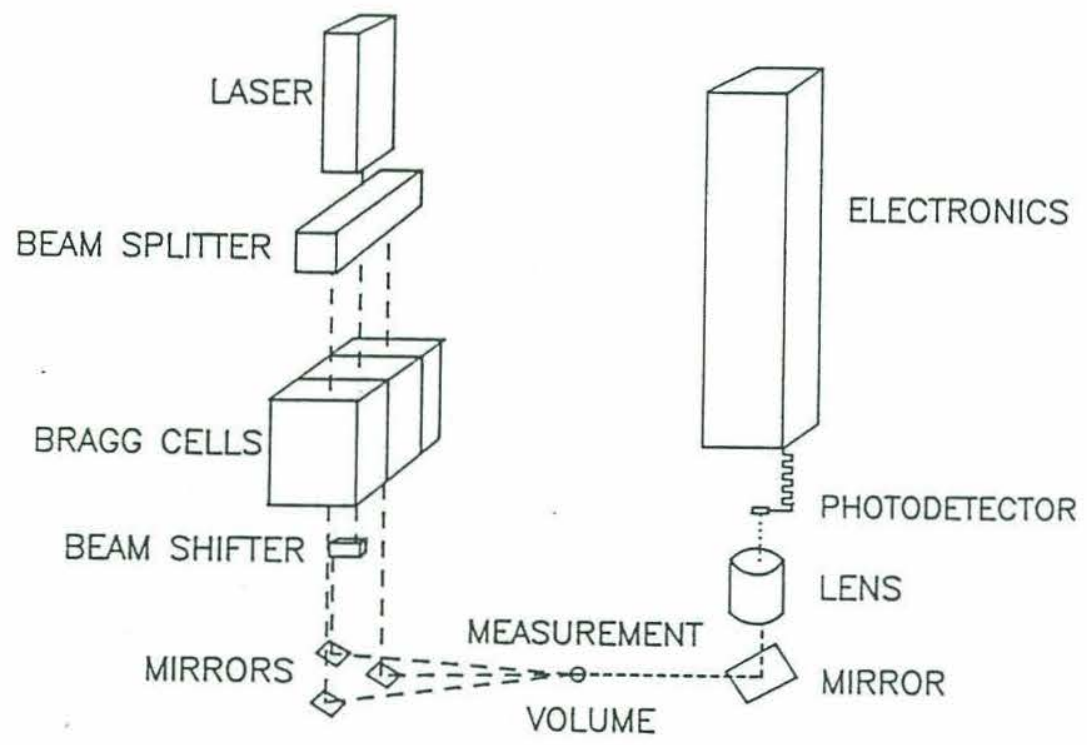

Figure 5: Schematic drawing of the laser-Doppler velocimeter.

The LDV system measures two components of velocity using a laser beam split into three beams that intersect at the measurement volume. The measurement volume is approximately ellipsoidal, with a long axis in the transverse direction of $1 \mathrm{~mm}$ in length and a circular crosssection of $0.3 \mathrm{~mm}$ in diameter. Within the measurement volume, one pair of beams (the $A$ channel) forms an interference pattern oriented $41^{\circ}$ upward, and another pair (the $B$ channel) generates a pattern oriented $44^{\circ}$ downward. The Doppler signals from the $A$ and $B$ channels are sent from the LDV microprocessor to the software package where an algebraic expression transforms the velocity to horizontal and vertical components. The measurement volume orientation and the algebraic expressions are given in Appendix I. 
Sending Optics: The source of laser light is a $8 \mathrm{~mW}$ Helium-Neon laser. The beam that is produced is red in color and has a wavelength of $623.8 \mathrm{~nm}$. The single beam is passed through a beam splitter that produces three equally spaced co-planer beams of equal power. The three beams are then passed through Bragg cells which shift the frequency of the laser beams. The common beam is shifted by $39.5 \mathrm{mHz}$ and the $A$ and $B$ beams are shifted by $38.5 \mathrm{mHz}$ and $43.5 \mathrm{mHz}$, respectively. Shifting the beams sets the fringe pattern in motion and also produces a carrier signal from which the Doppler signal can be filtered when processing the output of the photodetector. The center beam is then moved out of the plane so that the three beams form the corners of a triangle. The beams then hit mirrors which converge the triangle to a single point producing the measurement volume.

Receiving Optics: The image of the intersection volume is focused onto the photodetector using a $45^{\circ}$ mirror and the lens. Both the mirror and lens are adjustable to allow alignment of the system. The signal from the photodetector consists of two velocity signals, as well as noise. These signals consist of a carrier signal which is a sine wave that has a frequency equal to the frequency difference between the two intersecting beams. The $A$ and $B$ channels have $1 \mathrm{mHz}$ and $4 \mathrm{mHz}$ carriers, respectively. Superimposed on these carrier waves are the Doppler signals. The output of the photodetector is passed through a power splitter and mixer which only allows signals that are $1 \mathrm{mHz} \pm 30 \mathrm{kHz}$ or $4 \mathrm{mHz} \pm 30 \mathrm{kHz}$ to pass through. The two signals which are able to pass through the power splitter are produced by light scattering at the intersection volume. The signals are then passed through low-pass filters to remove the carrier signal, resulting in the Doppler frequency for the $A$ and $B$ channels. These signals are then passed to the microprocessor, which finds the predominant frequency for each channel and assigns a two-digit hexadecimal number corresponding to that frequency. The LDV microprocessor samples at each channel at $32 \mathrm{~Hz}$, and sends a block of data to the data-acquisition system once per second. The hexadecimal number is converted to velocity by multiplying it's decimal equivalent by $0.2649 \mathrm{~cm} \mathrm{~s}^{-1}$ (see Appendix I for calculation of this conversion constant). The resolution of the sampling scheme is $\sim 0.25 \mathrm{~cm} \mathrm{~s}^{-1}$.

\subsubsection{Data Acquisition and Processing Software}

The data acquisition and processing software was developed to give real-time information on the flow characteristics. By contrast, the LDV used in SEADUCT was a data-recording instrument using a communications program that received and recorded the hexadecimal velocity record for subsequent processing on the VAX system. The software developed for the flume incorporates the laser movement, control of the LDV microprocessor, and real-time processing into one integrated package.

The system processes the $32 \mathrm{~Hz}$ (changeable, with considerable effort, to $512 \mathrm{~Hz}$ ) velocity signal that is received in blocks from the LDV microprocessor once a second. The result of the processing is displayed on the screen in all of the various modes of data acquisition. A sample of the screen displaying real-time and accumulated results can be seen in Figure 6. The laser position, and the window filter values (the pre-set velocity limits which filter out wild points) are displayed at the top. The real-time section displays instantaneous horizontal and vertical 
velocities, percent drop-out (drop-out occurs when the Doppler signal is not strong enough to be processed), percent rejected by the window filters and the elapsed time. The realtime section is a one-second average and is updated every second. The accumulated section contains average streamwise $(\bar{u})$ and vertical $(\bar{w})$ velocities, standard deviations for the $u$ and $w$ velocities, $\overline{u^{\prime} w^{\prime}}=\operatorname{cov}(u, w)$ (the average product of the random fluctuating portion of the two velocity components), percent drop-out and percent rejected by the window filters. The accumulated section is averaged over the entire record and updated once a second.

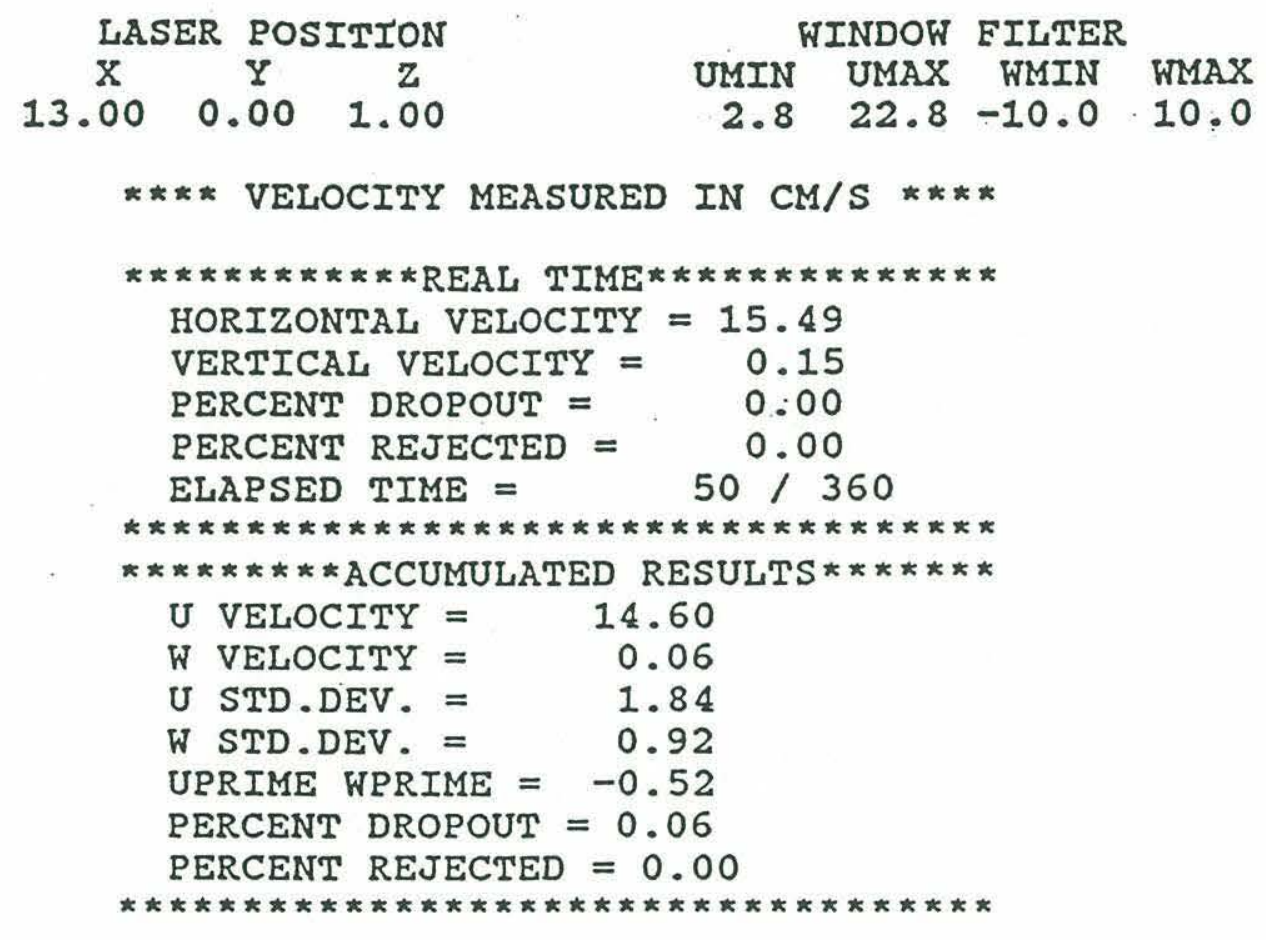

Figure 6: Sample of the data screen for the LDV software package which accompanies the 17-Meter Flume.

The system allows for four different modes of operation. 1) The current-meter mode is used for flow diagnostics when setting up a flow regime in the flume. This mode displays all the flow information but does not produce any data files. 2) The single-point mode allows data records to be generated at one position. 3) The automated-profiling mode is used to generate vertical and cross-stream profiles (sampling for a pre-set time interval at designated positions in the vertical or cross-stream). The locations where data are to be taken are entered initially and the system automatically executes the profile. 4) The time-series mode gives a velocity record at a single point over a set period of time. The real-time screen is displayed in all of the acquisition modes.

There are two options (which can be used simultaneously) for producing data records. 
One option creates hexadecimal raw data records which can be processed using the software processing programs described in this report or using the VAX programs developed for Dr. Agrawal's field LDV. The second option creates processed data in tabulated files that can be imported to a spread-sheet or a statistical program for plotting and statistical analysis.

The real-time processing software is written in Basic using Microsoft's QuickBasic. The system has been designed so that little computer knowledge is required to operate the menudriven system. The specifics of the software options and operations are described elsewhere (see 3.3).

\subsection{OTHER INSTRUMENTATION}

The other instrumentation associated with the flume is described in order of decreasing sophistication. Two instruments are used to measure the fluid discharge in the return pipe. The first is a fiberglass venturi flow element which measures the volumetric flow rate through the return pipe. The differential pressure between the flow in the pipe and the flow at the constriction created by the element is used to determine the discharge. The discharge $(Q$, in $\left.\mathrm{m}^{3} \mathrm{~s}^{-1}\right)$ is determined from the head $(H=\Delta p / \rho g$, where $p=$ pressure, $\rho=$ fluid density, and $g=$ acceleration due to gravity), presently measured in centimeters on a manometer, and from fluid density (in $\mathrm{g} \mathrm{cm}^{-3}$ ) according to the expression $Q=3.001 \times 10^{-3} \sqrt{\frac{H}{\rho}}$, where several dimensional quantities have been absorbed into the constant. The second is a Signet Flosensor which uses a small paddle wheel mounted in the return pipe to estimate the velocity at that point in the pipe. By assuming fully developed pipe flow, the discharge is calculated and displayed on a digital indicator. The slope of the flume is determined by using a pointer gauge that measures the change in elevation of the raceway at a location $13 \mathrm{~m}$ from the pivot point. The gauge consists of a pointer attached to a support that is anchored to the floor and a meter stick that is attached to the steel I-beam which supports the flume raceway. The weir and valve settings are measured using protractors mounted on the adjusting wheels. The depth of the flow is measured with rules mounted on the flume at three positions along the channel and adjusted so they all read the same value when the flume has zero slope.

An analog to digital board that mounts into one of the expansion slots in the PC also allows installation of transducers for the various flume settings and conditions. The board requires a 0 to 5 v.d.c. input, and therefore, signal conditioning will be required. There are no transducers installed on the flume at the time of this report.

\subsection{THE COOLING SYSTEM}

\subsubsection{Introduction}

The cooling system is designed to control the temperature of the water circulating in the flume. The temperature of the circulating water is influenced by three major factors; the heat 
input from the circulation pump, the heat removed by the cooling system, and the ambient room temperature. By balancing the heat input from the pump and the heat removed by the cooling system, it is possible to achieve a large range of operating temperatures for the flume. Higher-temperature flows (up to $10^{\circ} \mathrm{C}$ above ambient) are produced by running the flume until the heat from the pump has raised the water temperature to the desired level. Lowtemperature flows (down to a predicted $4^{\circ} \mathrm{C}$ ) are produced by running the cooling system at full capacity until the temperature reaches the desired level. Once the water is at the correct temperature, the microprocessor controller regulates the flow of coolant to maintain the set temperature. For more detailed information on the cooling system see Chapman \& Galat (1988).

\subsubsection{Description}

A schematic of the cooling system (Fig. 7) shows the basic operation of the refrigeration cycle. Heat is removed from the water in the basin as the R-12 coolent evaporates. The vapor is then circulated back to the condensing unit where it is condensed back to a liquid and compressed. The liquid then travels to the solenoid valve. If the temperature controller senses that the water temperature is too hot then the valve opens and the liquid travels to the expansion valve. The expansion valve returns the liquid to a low pressure and the R-12 flows into the heat exchangers where it evaporates and the cycle continues. There are four heat exchangers and four condensing units, each with their own expansion and solenoid valves. There are two temperature controllers, with each controlling half of the system.

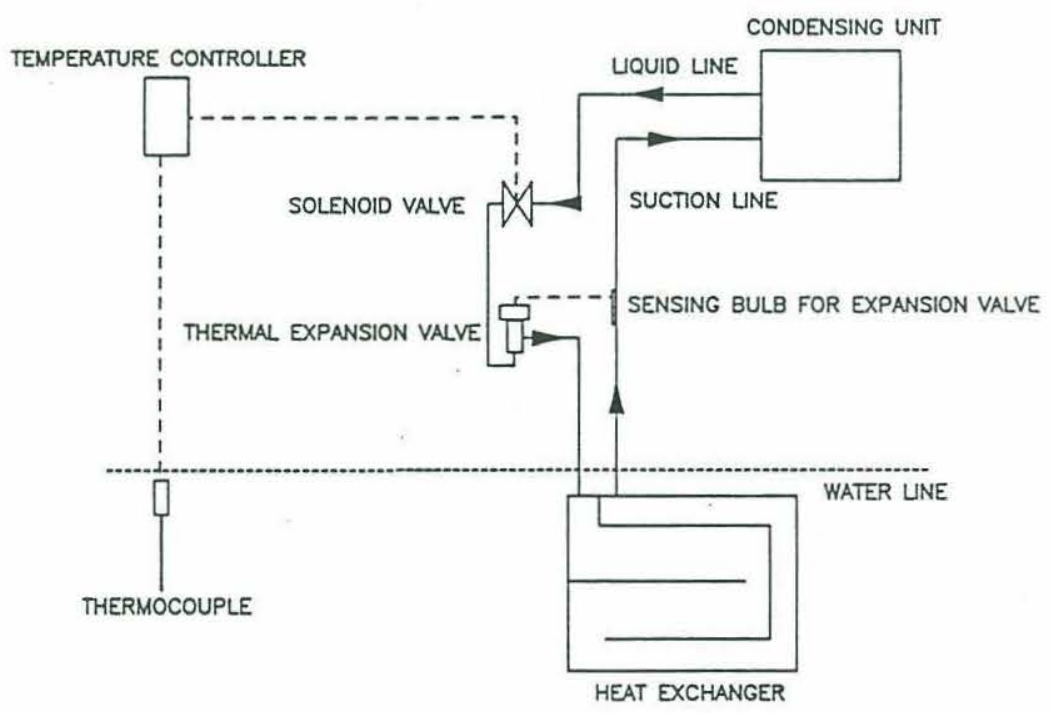

Figure 7: Schematic drawing of the flume cooling system. 
The panel-type heat exchangers are constructed of 0.6-mm-thick titanium sheets. The two sheets are welded together and the R-12 flows in a serpentine path through the panel. Each panel has $1.8 \mathrm{~m}^{2}$ of surface area and $30.5-\mathrm{cm}$-long titanium lead pipes. The panels were manufactured by Tranter and were halogen-leak tested, cleaned, dried and sealed for refrigeration service by the factory. The four heat exchangers are mounted vertically in a fiberglass rack in the center of the basin and aligned parallel to the main flow into the basin.

The Tecumseh condensing units are powered by $2 \mathrm{hp}$ electric motors and are located outside of the CRL. Each unit is capable of removing 19,500 BTU hr-1 from the system. The $\mathrm{R}-12$ is piped from the condensing unit to the heat exchangers via insulated copper piping. The four solenoid valves are mounted on the back wall of the CRL and each has a pilot light that is illuminated when the valve is open.

The Omega CN9000 temperature controllers are microprocessor driven and are fully programmable. Each controller uses a copper-constantan thermocouple probe to sense the temperature of the water. The connection between the probe and the return wire is potted in silicon to protect the connection from splash and moisture. The controllers have a digital display with a $0.1^{\circ} \mathrm{C}$ resolution. The microprocessor can be programmed using the four buttons located on the face below the display.

To reduce the amount of cooling capacity required to maintain the water temperature, all of the main components of the flume have been insulated (refer to Fig. 8). All piping has been wrapped with 2.5 -cm-thick black neoprene foam, with a manufacturer-quoted $R$ value of 4. The bottom and sides of the raceway are insulated with removable panels of foil-backed, closed-cell foam with an $R$ value of 14 . The top of the raceway has wood covers that are not insulated, to avoid the possibility of insulation entering the water and circulating through the system. The basin is covered by two removable panels constructed of wood and polyethylene sheeting to reduce heat loss due to induced convection over the basin.

Figure 8: Detailed drawing of the Thermax insulation panels (top) which cover the sides and bottom of the flume raceway, and of the foam insulation (bottom) that covers the return pipe (see Fig. 1).

\subsection{SAMPLE FLUME SETTINGS}

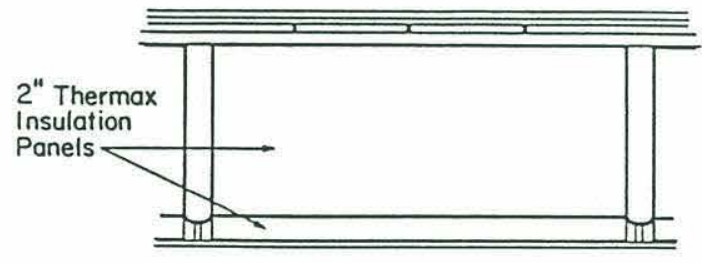

I - beam

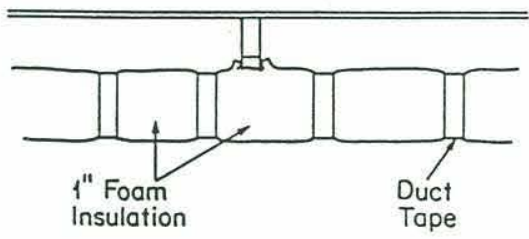

The 17-Meter Flume was designed to produce a flow that is driven against the retarding effect of boundary friction by a streamwise gravitational force produced by a sloping bottom 
(see Trowbridge et al., 1989). To eliminate a horizontal pressure gradient, the water surface in the sloping flume must be parallel to the flume bottom. This is accomplished, for a given discharge, by tilting the raceway and adjusting the weir so that water depth $h$ is identical everywhere along the channel, as described in Section 3.2. Sample flume settings for a selection of flows likely to be of interest to coastal oceanographers are given in Table 1 . The mean velocity and Reynolds stress profiles for these flows are shown in Figure 9. All flows are over the smooth PVC false bottom; flow characteristics may vary substantially if there is significant bottom roughness (e.g, see Trowbridge et al., 1989).

Table 1: Flume settings for flows shown in Figure 9. Water depth was $11.9-12.4 \mathrm{~cm}$ and water temperature was $20^{\circ} \mathrm{C}$, except for the $10 \mathrm{~cm} \mathrm{~s}^{-1}$ flow, where water temperature was $7^{\circ} \mathrm{C}$. $u_{*_{R}}$ is the boundary shear velocity calculated using the Reynolds stress technique, as described in Trowbridge et al. (1989).

\begin{tabular}{ccccccc}
$\begin{array}{c}\text { Nominal } \\
\text { Surface } \\
\begin{array}{c}\text { Velocity } \\
\left(\mathrm{cm} \mathrm{s}^{-1}\right)\end{array}\end{array}$ & $\begin{array}{c}\text { Valve } \\
\text { Position }\left(^{\circ}\right)\end{array}$ & $\begin{array}{c}\text { Slope of } \\
\text { Raceway } \\
\left(\times 10^{-4}\right)\end{array}$ & $\begin{array}{c}\text { Weir }^{a} \\
(\% \text { restriction })\end{array}$ & $\begin{array}{c}\text { Signet } \\
\text { Flowmeter } \\
\left(\mathrm{gal} \mathrm{min}^{-1}\right)\end{array}$ & $\begin{array}{c}\text { Venturi } \\
\text { Flowmeter } \\
\left(\mathrm{gal} \mathrm{min}^{-1}\right)\end{array}$ & $\begin{array}{c}\mathrm{u}_{*_{R}} \\
\left(\mathrm{~cm} \mathrm{~s}^{-1}\right)\end{array}$ \\
\hline 10 & $40^{*}$ & 0 & 94 & 54 & 98 & 0.50 \\
20 & $200^{*}$ & 1.2 & 84 & 100 & 125 & 0.81 \\
30 & $0^{* *}$ & 2.7 & 74 & 160 & 194 & 1.20 \\
40 & $170^{* *}$ & 4.8 & 65 & 212 & 254 & 1.56 \\
50 & $35^{* * *}$ & 7.4 & 54 & 282 & 328 & 2.00 \\
\hline
\end{tabular}

a From measurements of the openings (cross-stream distance) between blades in the weir, and reported as a percentage of the total cross-stream width $(60 \mathrm{~cm})$.

* indicates number of full turns of valve prior to obtaining position shown:

${ }^{*}=$ one turn, ${ }^{* *}=$ two turns, ${ }^{* * *}=$ three turns. 

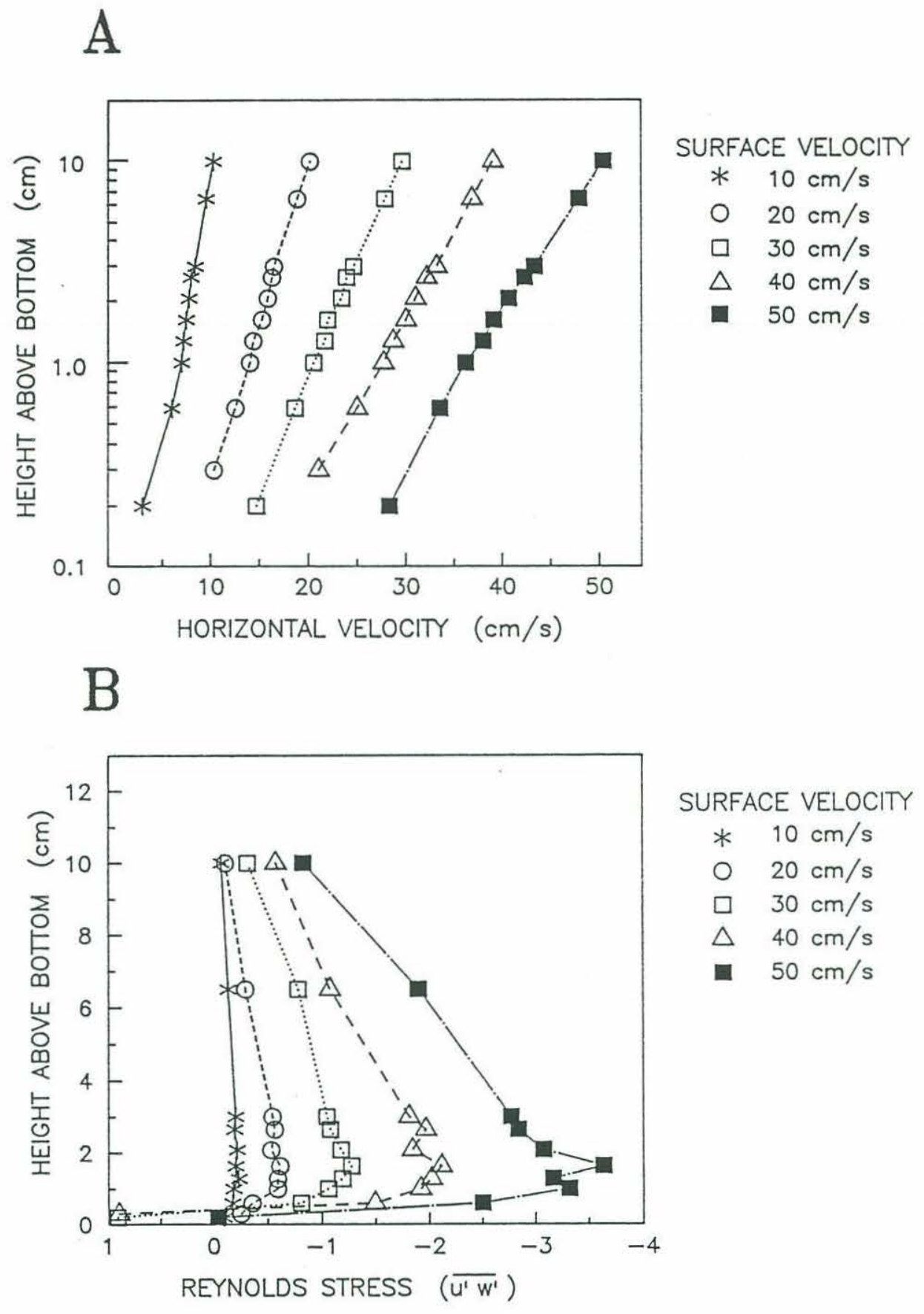

Figure 9: Profiles of mean velocity (A) and Reynolds stress (B) for a selection of flows. Refer to Table 1 for flume settings. 


\section{INSTRUCTIONS FOR USE}

Checklists for start-up and shut-down of the flume are given in Appendix II.

\subsection{FILL UP}

Note: When filling the flume, first check to make sure sump valve is closed, and have someone on site responsible at all times to avoid flooding the CRL!

Freshwater: Filling the flume basin to a depth that completely covers the cooling panels with freshwater requires roughly 8 hours. The water tap is located on the vertical beam at the bottom of the stairs leading to the platform surrounding the Deep Submergence Laboratory's (DSL) test tank (Fig. 10). The hose is also stored at the bottom of the stairs. Fill the main basin until the water surface is midway up the titanium pipes that lead to the heat exchangers. Care should be taken not to fill the basin beyond the top of the titanium pipes. The pipes under the black insulation are copper; leaching could result if the water level is too high, and copper is toxic to many organisms.

Seawater: To fill the flume with seawater requires 10 to 14 hours, depending on the number of other users of the seawater system at the CRL. Prior to filling the flume sump, check with other seawater users at the CRL because the seawater volume entering the CRL is not sufficient to accommodate all users simultaneously, without temporarily depriving one or more of the users. The seawater value is located on the wall with windows at the downstream end of the flume, in the region of the sump (Fig. 10). Cartridge filter holders are attached to the spigot and a garden hose screws onto the filter outlet. The seawater must be filtered to prevent fouling of the system. The greater the filtration the longer the period to fill the system. Cartridge filters are available at the flume facility in $1-$ and $10-\mu \mathrm{m}$ sizes. Filtering with a $10-\mu \mathrm{m}$ filter is adequate for most studies and gives the best LDV signal. When $1-\mu \mathrm{m}$ filtered water is required, the $10-\mu \mathrm{m}$ and $1-\mu \mathrm{m}$ filters should be placed in serial, the $10-\mu \mathrm{m}$ filter acting as a prefilter. The seawater tap and filters are located on the side wall of the CRL next to the basin. The seawater comes from an intake pipe located offshore of the CRL in Vineyard Sound. Fill the water to the level specified in the freshwater section.

\subsection{START UP}

Step One: There are three main circuit breakers (refer to Fig. 10) that must be turned on to activate the power supply to the flume. Two of the breakers are located on the wall to the right just after entering the high bay area of the building; they are labeled "Flume Lift Pump" and "Flume Water Pump". The third box is located at the base of the stairs that lead up to the DSL platform, and is labeled "Flume Pump Control". 
Step Two: The pump requires a freshwater supply to protect the impeller bearings. The valve for the freshwater is located on the basin wall behind the pump (Fig. 10). There is a pressure gauge attached to the valve; make sure that the pressure is at least $20 \mathrm{psi}$. The water from the bearing protection system discharges from a small copper pipe into the drainage channel right below the raceway pivot. Visual verification of discharge from this pipe ensures that the pump is receiving a continuous supply of water.

Step Three: Check that there is nothing within the raceway that could be swept into the settling basin. Small objects could make their way through the protective mesh at the bottom of the basin and damage the pump. Check that the vertical blinds are in an open position, and that the end box is diverting the flow into the correct basin.

Step Four: Open the main valve one turn. Press the low speed button on the power switch which is adjacent to the pivot point on the steel I-beam that supports the raceway (see Figs. 1 and 10). The pump must operate at the low speed. The impeller currently installed in the pump was designed to operate at this low speed and operating at the high speed may damage the pump.

Step Five: Adjust the flume controls to achieve the desired flow. Sample settings are given in Table 1. To obtain flows not presented, estimate volumetric discharge and the mean bottom shear stress $\left(\tau_{b}\right)$ for the required depth and velocity. Adjust the hydraulic jack to obtain the slope that results from solving for $\theta$ (the slope of the flume from the horizontal) in the equation, $\tau_{b}=\rho g h \sin \theta$, (see Trowbridge et al., 1989) using your estimated $\tau_{b}$. Using water depth and the Signet Flosensor as guides, adjust the main valve and the weir to develop a flow that is roughly the desired condition. Fine-tuning of the flow is achieved by using the LDV to monitor velocity while finely adjusting the weir to obtain the desired velocity. When the desired velocity is achieved, adjust the main valve to achieve the desired water depth. This is an iterative procedure.

\subsubsection{Shut Down}

Step One: Turn off pump and close all valves. Turn off water supply to the pump impellers, and then all circuit breakers. Return flume slope to zero after all water has drained from raceway.

Step Two: If using seawater or if the freshwater has become dirty, then draining the basin is required. The drain valve for the main basin is located underneath the basin in the supply feed pipe. Entry to the sub-basin area is made through the trap door directly below the bypass valve (Fig. 10). An automatic sump pump transfers the drainage from the sub-basin area to the drainage channel. To avoid flooding the CRL, only open the valve one-quarter turn and make sure that the 


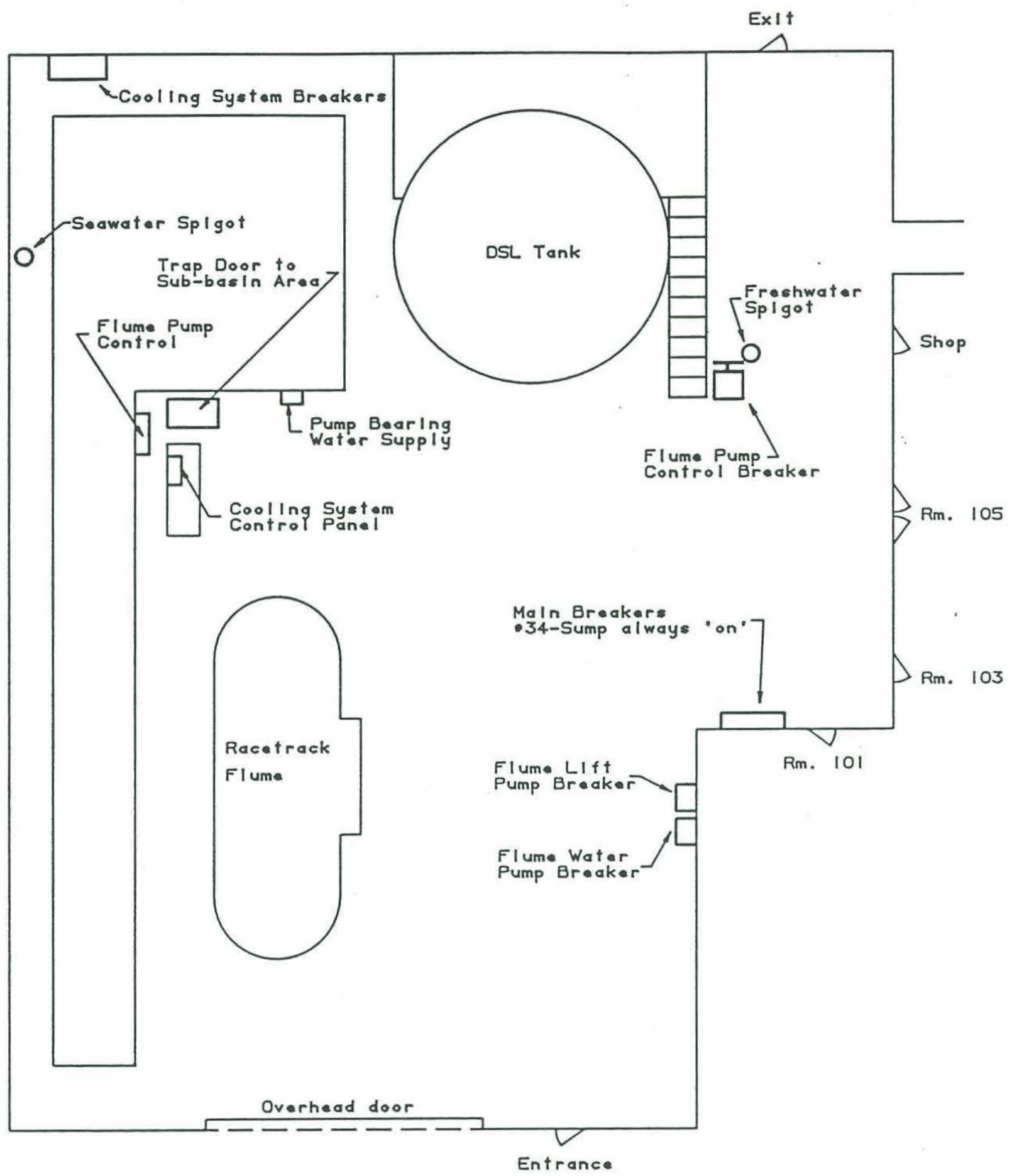

Figure 10: Diagram (not to scale) of the high-bay area at the CRL showing locations of instruments and equipment relevant to flume operations. 
sump pump is operating correctly before leaving the flume. The circuit breaker for the sump pump is \# 34 in the "Main Breaker" box (Fig. 10) and should always be "on".

\subsection{LDV OPERATION}

\subsubsection{General Comments}

The LDV is a delicate instrument. The alignment of the receiving and sending optics can be altered if the LDV is jarred. Misalignment will be reflected in a high drop-out rate. If this occurs, contact the flume technician (through the CRC administration) for instructions on realignment.

\subsubsection{Start Up}

Step One: Connect extension cord to the power strip located on the LDV cart on top of the flume (see Fig. 1). Connect the two RS-232 communication cables from the LDV cart to the computer. The cables are color-coded. The yellow cable goes from COM 2 on the computer to the stepper motor controllers and the green cable goes from COM 1 on the computer to the LDV microprocessor.

Step Two: Turn on the computer. Once the computer has booted, the operating system menu will appear. Select the '17-Meter Flume LDV' option from this menu. This option will start up the menu-driven software. If the program prompts 'Enter', then type in the required information and hit the enter key. If the program prompts 'Hit', then press the desired key and do not press the enter key. For a detailed explanation of the menu options see 3.3.4 - 3.3.7.

\subsubsection{Shut Down}

Step One: Select the 'Exit From Program' option from the data acquisition menu so that the main menu will appear. Select the 'Return to System' option. To protect the hard disk, retract the read/write head from the hard disk. This is done by typing: 'Retract $\langle$ Enter $\rangle$ '. Turn the power to the computer off.

Step Two: Located on the communications cable (green) for the LDV, there is a spring-loaded toggle switch. This switch must be held in the "on" position when the power strip for the LDV is turned off. It is important that this switch is activated when powering down the laser to avoid microprocessor hang-up. If the microprocessor hangs-up, contact the flume technician for assistance. 


\subsubsection{Software - Main Menu}

The first menu that appears upon entering the software is the main menu. The main menu allows easy access to the most-frequently used programs. There are other programs that allow for more detailed analysis of the data. These programs and their instructions are available upon request. The following is a description of the four options in the main menu.

Data Acquisition. This will start-up the program used to communicate with the LDV and the stepper motors. This is the main part of the software.

Data Processing. This will bring you into a program which allows processing of existing raw data files. The program gives options for data filtering. The output format of this program is the same as that of the Data Acquisition.

Printing Files. This option permits print-out of the processed files without returning to the MS-DOS operating system. Instructions for printing files are given at the start of this option.

Return to Main System. This will bring you into the operating system menu.

Executing the data acquisition option begins the LDV start-up routine. The screen will display the instructions for powering up the system. When the instructions have been completed hit " $\mathrm{B}$ " to continue. Next the LDV boot-up test will be displayed on the screen. This test checks to see that the laser is responding correctly to the program. The correct responses that the program is expecting are followed by a $\left({ }^{*}\right)$ and the laser responses are followed by a (?). The program will ask whether or not the LDV responded correctly. If the answer is "no" then the program will try again and if the answer is "yes" then the next screen will ask if the most recent parameters are to be installed. The most recent parameters consist of the LDV position, the range of the window filters, the measurement period, and if the program had crashed during a profile, it will also contain information that will allow the profile to continue where it left off.

The data-acquisition menu will now be displayed. The laser position is displayed at the top of the menu. The options available and descriptions of their use are listed below.

\subsubsection{Laser Movement}

The coordinate system for the laser is defined as follows. The $x$-axis runs parallel to the raceway (i.e., in the streamwise direction) with the origin at the entrance to the raceway; downstream is the positive direction. The $y$-axis runs cross-stream with the center of the flume being the origin; facing downstream, the positive side is to the right of the origin. The $z$-axis runs in the vertical direction and the origin is the flume bottom. 
Horizontal Movement. With this option the program will display a prompt for the new horizontal position. Enter the $y$-coordinate for the position to which the laser is to be moved.

Vertical Movement. This is similar to option 1 ; enter the $z$-coordinate for the desired position.

Enter the Coordinates. This option sets the $x, y$, and $z$ coordinates allowing for creation of any reference frame. Once the new coordinate system has been established, all movement is with respect to the new coordinate system.

\subsubsection{Measurement Parameters}

The measurement parameters must be set properly prior to entering into any of the measurement options.

Measurement Period. The measurement period is the length of time, in seconds, that the LDV will send data to the computer. In the profiling mode, measurement period is the length of the data record at each point in the profile. In time-series mode, measurement period is the length of time over which data is to be taken.

Window Filter. This is a filter (wild-point editor) that eliminates points from the data stream which are outside a specified rectangular window. The window is based upon a mean velocity which is taken prior to the data record. This filter prevents wild points from influencing the real-time processing. The program will display a prompt for the half range of the filter in $\mathrm{cm} \mathrm{s}^{-1}$. The half range is added to the mean for the upper limit and subtracted from the mean for the lower limit. The program then displays a prompt for the length of time over which to calculate the mean for the window. The window is recalculated at each new laser location.

Cancel Filters. This option turns off the window filtering.

\subsubsection{Measurement Options}

When data recording options are chosen, the program will ask for file management information. The output files will contain the name of the experiment, the initials of the person taking the data, the date and time, and a brief description of the experiment (optional). The program needs to know if raw and or processed files are to be produced. The program will ask for a rootname for the file. Raw data files will have names that consist of the rootname plus an extension that is made up of " $R$ " and a two-digit number. In profiling mode the raw data for the first point is called 'rootname.R0O' and each subsequent point in the profile 
increments the two-digit counter by one. Processed data files have names that consist of the rootname plus the extension '.PRO'.

Current Meter. This will display the real-time screen and there will be no data record created.

Data Recording. This option is for recording data for a single point.

Continue Data Recording. This option will allow recording of data onto the same file created in the 'Data Recording' mode.

Profiling Mode. This option is the automatic profiling package. The maximum number of locations in a profile is 100 . The program will ask for the number of points in the vertical and then for the locations of these points. The program then displays a prompt for the number of cross-stream locations that the vertical profile should be repeated and for the coordinates for these points.

Time Series. This option allows for a detailed record at a single point. The program will display a prompt for the length of the processing (= averaging) interval. In contrast to the 'Data Recording' option, where the processing interval is equivalent to the entire length of the record, the processing interval in the "Time Series' option can be selected.

Dump Data. This will print the raw hexadecimal data on the screen. No data records are created.

Leave Program. This will exit from 'Data Acquisition'.

\subsection{COOLING SYSTEM OPERATION}

\subsubsection{Start Up}

Step One: The cooling-system fuse box is located on the back wall of the CRL, behind the basin (Fig. 10). Turn on all of the circuit breakers.

Step Two: Start circulating the water in the flume and open the bypass valve (Fig. 1) at least two turns. Water circulation is required to maintain a high coefficient of heat transfer between the heat exchanger panels and the water in the basin, and to prevent the panels from freezing up.

Step Three: The on-off switch is located on the side of the "Cooling System Control Panel" (Fig. 10) which contains the temperature controllers and the Signet Flosensor. When the system is turned on the temperature controllers will display the system temperature. The controllers will initially display the incorrect 
temperature until they have "warmed up"; the manufacturer quotes a 20-min warm-up period.

Step Four: The temperature controllers display the system temperature and when the "*" button is pressed they display the set-point temperature. To change the set-point temperature, hold down the "*” button and press the " $\uparrow$ " button to increase or the " $\downarrow$ " button to decrease the set-point temperature.

Note: When the air temperature is warmer than the water temperature, air condenses on the flume windows. A fan assembly which blows compressed air across the outside of a section of the windows on either side of the flume is available to permit LDV measurements under these conditions. The fan assembly is located on the cart holding the LDV and stepper motors.

\subsubsection{Shut Down}

Step One: Turn the on-off switch "off". If there is a large temperature differential between the flume water and the room temperature, then keep the flume running until the temperature of the water is close to room temperature. The heat from the pump will gradually warm up the water. This step is done to prevent the glass windows from cracking due to thermal stresses resulting from a large temperature differential on either sides of the glass.

\section{ACKNOWLEDGMENTS}

The 17-Meter Flume would not exist if it were not for the vision, persistence and energy of Dr. William D. "Bill" Grant (deceased, 6 October 1986). Bill lived long enough to see water recirculate in the flume but, sadly, experienced neither the thrill of watching the LDV automatically profile vertically and cross-stream for hours on end, nor the satisfaction of completing a research project which would not have been possible without the flume. His inspiration surely has driven the level of effort invested in all tasks required to equip the flume for research, and we are grateful for the sense of his presence that pervades the atmosphere of the flume facility at the CRL.

Bill designed the flume in collaboration with Ken Doherty, who continues to provide advice on a multitude of mechanical-engineering issues associated with the flume. Personnel at Ontario's National Water Research Institute Hydraulics Laboratory were helpful during a visit by Ken to this facility to discuss the early plans for the flume design. The LDV was designed and constructed by Dr. Yogi Agrawal and Chris Belting. In conjunction with Yogi and Chris, the stepper-motor assembly and early software development were the brainchildren of Dr. Tom Gross. The cooling system design was launched by a trip to the U.S. Army Corp of Engineers' Cold Regions Research and Engineering Laboratory (Essex, N.H.) and we are especially grateful for the time and advice of Jim Wuebben and Steve Daly. We 
also extend our appreciation to WHOI Facilities, especially Rick Galat, for their interest and cooperation in installing the cooling system.

After Bill's Death, the senior author relied heavily on the advice and support of many colleagues regarding this project. She would especially like to thank Drs. Dave Aubrey, Brad Butman, Dave Cacchione, Rocky Geyer, Tom Gross, Arthur Nowell, Keith Stolzenbach and John Trowbridge. Dr. Lauren Mullineaux and Charlotte Fuller were instrumental in finally getting alot of things to work, but we particularly thank them for always lending a hand (or two or more!). We also thank Shirley Bowman for patiently typing numerous versions of this manuscript, Laurie Raymond for her artistry (especially Figure 1), and Drs. Aubrey, Geyer and Trowbridge for comments on the manuscript.

Funding for construction of the 17-Meter Flume and the LDV were provided by WHOI's Coastal Research Center and we are indebted to the two Directors of the CRC, Drs. John Farrington and Dave Aubrey, for continuing to come up with the resources to fund all the "unexpecteds" and for their untiring belief in and patience with this project. CRC funds were derived primarily from the Mobil Foundation and the Richard King Mellon and Andrew W. Mellon Foundations. The cooling system and other miscellaneous instrumentation was funded by a Minerals Management Service, Department of the Interior, contract (No. 1412-0001-30262 to the senior author. Salary support for the authors and other personnel involved in this project was provided by the CRC, and grants to the senior author from the MMS, NOAA National Sea Grant College Program Office, Department of Commerce (Grant No. NA86-AA-D-SG090, WHOI Project No. R/P-26), the Office of Naval Research Young Investigator Program (Contract No. N00014-86-K-0579) and the Walter A. and Hope Noyes Smith Special Studies Award at WHOI. The U.S. Government is authorized to produce and distribute reprints for governmental purposes notwithstanding any copyright notation that may appear hereon.

\section{LITERATURE CITED}

Agrawal, Y.C. and C.J. Belting. 1988. Laser velocimetry for benthic sediment transport. Deep-Sea Res. 35: 1047-1067.

Chapman, R.J. and R.E. Galat. 1988. Cooling the waters of the 17-Meter Flume at the Coastal Research Laboratory. W.H.O.I. Tech. Rept. 88-62. CRC Tech. Rept. 88-1, $15 \mathrm{pp}$.

Durst, F., A. Melling and J.H. Whitelaw. 1976. Principles and Practice of Laser-Doppler Anemometry. Academic Press, N.Y., 405 pp.

Kobayashi, N. and O.S. Madsen. 1985. Turbulent flows over a wavy bed. J. Geophys. Res. 90: 7323-7331.

Nezu, I. and W. Rodi. 1986. Open channel flow measurements with a laser Doppler anemometer. J. Hydraulic Eng. 112: 335-355. 
Nowell, A.R.M., I.N. McCave and C.D. Hollister. 1985. Contributions of HEBBLE to understanding marine sedimentation. Mar. Geol. 66: 397-409.

NWRI. 1982. National Water Research Institute Hydraulics Laboratory, brochure describing facility, published by Minister of Supply and Services, Cat. No. En 37-59/1982, $51 \mathrm{pp}$.

Toman, K. 1984. Christian Doppler and the Doppler effect. EOS 65(48): 1193-1194.

Trowbridge, J.H., W.R. Geyer, C.A. Butman and R.J. Chapman. 1989. The 17-Meter Flume at the Coastal Research Laboratory. Part II: Flow characteristics. W.H.O.I. Tech. Rept. 89-11. CRC Tech. Rept. 89-s, 37 pp.

Vanoni, V.A. 1946. Transportation of suspended sediment by water. Trans. Amer. Soc. Civil. Eng. III, paper no. 2267, 67-133.

\section{APPENDIX I}

\subsection{LASER GEOMETRY}

\subsubsection{Measurement Orientation}

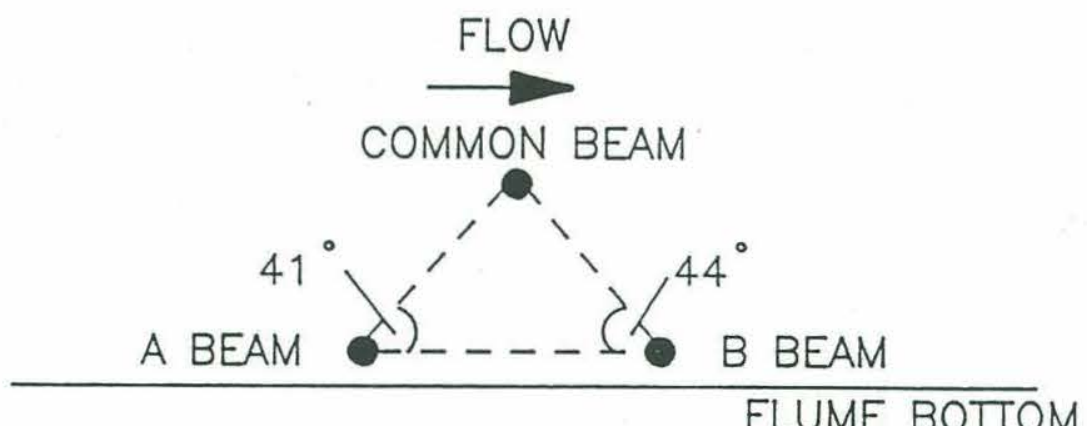

\subsubsection{Beam Geometry}

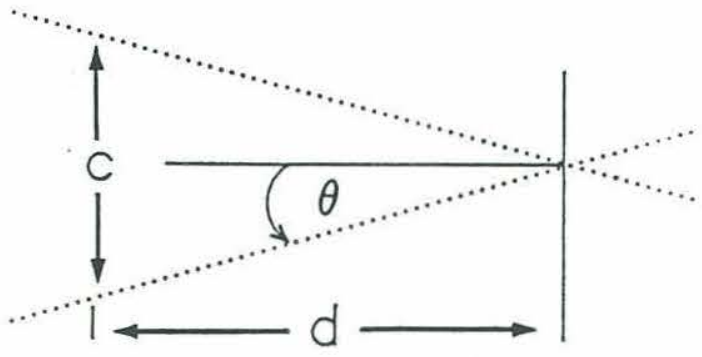

$$
\begin{aligned}
& c=1.35 \mathrm{~cm} \\
& d=30.48 \mathrm{~cm} \\
& \theta=\tan ^{-1} \frac{c / 2}{d} \\
& \theta=2.21 \cdot 10^{-2} \mathrm{rad}
\end{aligned}
$$




\subsection{CONVERSION CONSTANT}

$$
\begin{aligned}
& f_{D}=\frac{2 n \sin \theta}{\lambda} U_{p} \\
& \text { where } \quad f_{D}=\text { difference frequency } \\
& n=\text { refractive index of fluid } \\
& \theta=\text { half-angle of beams } \\
& \lambda=\text { wavelength of laser beam } \\
& U_{p}=\text { velocity of particle } \\
& \lambda_{\text {laser }}=6.33 \cdot 10^{-5} \mathrm{~cm} \\
& n_{\text {water }}=1.33 \\
& \sin \theta=2.21 \cdot 10^{-2} \\
& f_{D}=\left[\begin{array}{c}
\text { conversion } \\
\text { factor }
\end{array}\right] \cdot\left[\begin{array}{c}
\text { processor } \\
\text { output }
\end{array}\right] \\
& \text { crystal frequency } \\
& \text { where } \begin{array}{c}
\text { conversion } \\
\text { factor }
\end{array}=\left[\begin{array}{c}
\text { clock cycles } \\
\text { bin }
\end{array}\right]\left[\begin{array}{c}
\text { number } \\
\text { of bins }
\end{array}\right] \\
& \text { processor output }=\begin{array}{c}
\text { hexadecimal number } \\
\text { corresponding to most } \\
\text { predominant frequency }
\end{array} \\
& \text { crystal frequency }=2.015 \cdot 10^{6} \mathrm{~Hz} \\
& \underset{\text { bin }}{\text { clock cycles }}=16 \\
& \underset{\text { of bins }}{\text { number }} \quad=\quad 512 \\
& f_{D} \quad=245.97 \mathrm{~Hz} / \mathrm{bin} \\
& U_{p}=0.2649 \mathrm{~cm} / \mathrm{s} / \mathrm{bin}
\end{aligned}
$$




\section{APPENDIX II}

\subsection{FLUME OPERATION CHECKLIST: START UP}

1. Turn on circuit breakers ( 3 main breakers for flume and the cooling system breakers)

2. Turn on water supply to pump impellers and check that water is discharging through copper pipe under raceway and that the pressure gauge on the pump valve reads at least $20 \mathrm{psi}$

3. Set flume slope

4. Open bypass (2-turn minimum when using cooling system)

5. Check raceway for objects

6. Set weir

7. Open valve one turn and start pump (use low speed button only)

8. Turn on cooling system (do not use if water does not completely cover cooling panels in sump)

9. Post notices stating who to contact in case of a problem (include home phone number if flume will be operating during off hours)

10. If appropriate, tape open light switches in high bay and notify guards

\subsection{FLUME OPERATION CHECKLIST: SHUT DOWN}

1. Turn off pump and close valves

2. Turn off water supply to pump impellers

3. Turn off all circuit breakers

4. Lower flume raceway to zero slope after channel has drained completely

5. If draining basin, first drain pipe under raceway, then open drain valve $1 / 4$ turn and make sure that sump pump is operating before leaving CRL 


\section{DOCUMENT LIBRARY}

May 5, 1989

Distribution List for Technical Report Exchange

Attn: Stella Sanchez-Wade

Documents Section

Scripps Institution of Oceanography

Library, Mail Code C-075C

La Jolla, CA 92093

Hancock Library of Biology \& Oceanography

Alan Hancock Laboratory

University of Southern California

University Park

Los Angeles, CA 90089-0371

Gifts \& Exchanges

Library

Bedford Institute of Oceanography

P.O. Box 1006

Dartmouth, NS, B2Y 4A2, CANADA

Office of the International Ice Patrol

c/o Coast Guard R \& D Center

Avery Point

Groton, CT 06340

Library

Physical Oceanographic Laboratory

Nova University

8000 N. Ocean Drive

Dania, FL 33304

NOAA/NESDIS Miami Library Center 4301 Rickenbacker Causeway

Miami, FL 33149

Library

Skidaway Institute of Oceanography

P.O. Box 13687

Savannah, GA 31416

Institute of Geophysics

University of Hawaii

Library Room 252

2525 Correa Road

Honolulu, HI 96822

Library

Chesapeake Bay Institute

4800 Atwell Road

Shady Side, MD 20876

MIT Libraries

Serial Journal Room 14E-210

Cambridge, MA 02139
Director, Ralph M. Parsons Laboratory

Room 48-311

MIT

Cambridge, MA 02139

Marine Resources Information Center

Building E38-320

MIT

Cambridge, MA 02139

Library

Lamont-Doherty Geological

Observatory

Colombia University

Palisades, NY 10964

Library

Serials Department

Oregon State University

Corvallis, OR 97331

Pell Marine Science Library

University of Rhode Island

Narragansett Bay Campus

Narragansett, RI 02882

Working Collection

Texas A\&M University

Dept. of Oceanography

College Station, TX 77843

Library

Virginia Institute of Marine Science

Gloucester Point, VA 23062

Fisheries-Oceanography Library

151 Oceanography Teaching Bldg.

University of Washington

Seattle, WA 98195

Library

R.S.M.A.S.

University of Miami

4600 Rickenbacker Causeway

Miami, FL 33149

Maury Oceanographic Library

Naval Oceanographic Office

Bay St. Louis

NSTL, MS 39522-5001

Marine Sciences Collection

Mayaguez Campus Library

University of Puerto Rico

Mayagues, Puerto Rico 00708 